\title{
Mapeamento de Órbitas em torno do Asteróide 2001SN263
}

\author{
ANTÔNIO F. B. A. PRADO \\ Instituto Nacional de Pesquisas Espaciais- INPE \\ 12227-010, São José dos Campos, SP, Brasil \\ E-mail: prado@dem.inpe.br
}

\begin{abstract}
Resumo: O presente trabalho tem o objetivo de efetuar um mapeamento de trajetórias que tenham um bom potencial para mostrar um baixo consumo de combustível nas manobras de manutenção orbital para uma nave espacial viajando ao redor do asteróide 2001SN263. Este asteróide é um sistema composto por três corpos, que estão em uma órbita elíptica em torno do Sol. As perturbações consideradas na trajetória da nave espacial são devidas aos dois corpos menores do sistema triplo, do Sol, da Lua e de todos os planetas do Sistema Solar. A principal razão para estudar essas trajetórias é que, atualmente, existem várias instituições no Brasil estudando a possibilidade de realizar uma missão cujo objetivo é enviar uma nave espacial para este asteróide, porque há muitos estudos científicos importantes que podem ser realizados em torno dele.
\end{abstract}

Abstract: The present paper has the goal of mapping trajectories that have good potential to show low fuel consumption for station-keeping maneuvers for a spacecraft travelling around the asteroid 2001SN263. This asteroid is a system composed by three bodies that are in an elliptic orbit around the Sun. The perturbations considered in the trajectory of the spacecraft are due to the two satellite bodies, the Sun, the Moon and all the planets of the Solar System. The main reason to study those trajectories is that, currently, there are several institutions in Brazil studying the possibility to make a mission to send a spacecraft to this asteroid, because there are many important scientific studies that can be made around it.

Palavras-chave: Astrodinâmica, perturbações orbitais, terceiro corpo.

\section{Introdução}

Entre as órbitas de Marte e Júpiter existe uma grande concentração de corpos celestes. Essa região é conhecida como cinturão de asteróides. Uma parte específica dessa região é formada por corpos cujas órbitas cruzam com a dos planetas interiores do Sistema Solar. São os chamados NEA (Near-Earth Asteroid).

Acredita-se que a maioria desses asteróides conserva informações sobre a composição original do disco que formou o Sistema Solar. Sendo assim, é de grande interesse científico o estudo desses corpos, pois representam um laboratório de como era o Sistema Solar na época de sua formação. Também se especula em asteróides como fontes de minerais e de elementos químicos raros. Apesar de todo esse interesse, poucas missões espaciais com esse objetivo foram lançadas até hoje.

Para esse tipo de estudo, um dos candidatos mais interessantes e o asteróide 2001SN263. Trata-se na verdade de um sistema triplo, que foi observado em fevereiro de 2008, pela estação de radioastronomia de Arecibo, em Porto Rico. Os componentes possuem diâmetros de cerca de $2,8 \mathrm{~km}, 1,2 \mathrm{~km}$ e $0,5 \mathrm{~km}$. Assumindo um sistema de referencia centrado no corpo maior, observa-se que o segundo componente tem semi-eixo maior de $16,63 \mathrm{~km}$ e o terceiro componente tem semi-eixo maior de $3,80 \mathrm{~km}$.

Nesse sentido, surge o projeto ASTER (Sukhanov et al., 2010), que consiste no envio de um veículo espacial ao asteróide $2001 \mathrm{SN} 263$. Um primeiro cronograma prevê o lançamento em 2017, para uma visita com duração em torno de um ano.

Trata-se de um projeto de grande porte, envolvendo diversas instituições brasileiras, tais como INPE,
UNESP, UnB, ON, UFABC, UFRJ, USP, UFPr, UEFS, ITA, IMT, UNICAMP, UFF e MAST.

Além do conhecimento científico, diversos produtos tecnológicos são esperados dessa missão, tais como a validação de diversos equipamentos, propulsores, etc, bem como a formação de recursos humanos nas diversas áreas envolvidas.

O objetivo do presente trabalho é efetuar um estudo dinâmico das forças perturbadoras que agem nas imediações do corpo principal do asteróide triplo 2001SN263. Para isso, serão consideradas órbitas em torno desse corpo principal e serão estudadas as forcas perturbativas atuantes.

A abordagem utilizada no presente trabalho é baseado na integral ao longo do tempo das forças perturbadoras que atuam na nave espacial (Prado, 2013). Esta integral mede o efeito total das perturbações na espaçonave. Supõe-se que órbitas com valores mais baixos para essa quantidade requerem mais tempo para ter a órbita alterada significativamente, e por isso vai exigir um menor consumo de combustível para manobras de manutenção orbital.

Esta integral é uma característica do conjunto de perturbações consideradas para a órbita da nave espacial, de modo que seu valor não depende da técnica ou do tipo de motor utilizado para as manobras orbitais. Então, essa quantidade pode ser vista como um critério para selecionar possíveis órbitas para a nave espacial.

Os resultados mostram que existe uma dependência deste índice com a geometria relativa inicial dos corpos, portanto, um estudo foi feito considerando-se uma média das posições iniciais dos corpos perturbadores, que são especificados pelas anomalias verdadeiras de cada corpo.

Assim, pode-se encontrar as órbitas que são mais 
adequadas, em relação às perturbações sofridas pela nave espacial, para realização da missão.

\section{Modelagem Matemática}

Esta parte do trabalho apresenta as equações dadas pelo modelo matemático utilizado para estudar o problema. Supõe-se a existência de um corpo principal com uma massa $\mathrm{m}_{0}$, fixo no centro do sistema de referência xyz. Esse corpo é o asteróide de maior massa do sistema triplo, nos calculos aqui efetuados. Há também um corpo que está perturbando o movimento do satélite (que serão os dois corpos menores do asteróide, o Sol, a Lua e os planetas do Sistema Solar, sempre considerados individualmente), com massa $\mathrm{m}$ ', que é assumido como estando em uma órbita circular em torno do centro do sistema de referencia, no caso dos dois corpos menores e do Sol, com semi-eixo maior a' e movimento médio n'. No caso dos planetas do Sistema Solar, eles são assumidos como estando em órbitas circulares em torno do Sol, ainda com massa m', semi-eixo maior a' e movimento médio n'. O plano da órbita é assumido como sendo o plano equatorial xy. A nave espacial está em uma órbita elíptica tridimensional que tem elementos orbitais: a (semi-eixo maior), e (excentricidade), i (inclinação), $\omega$ (argumento do periélio), $\Omega$ (longitude do nódo ascendente) e com movimento médio n. Assim, a magnitude da força por unidade de massa atuando no veículo espacial devido a ação do corpo perturbador é dada por:

$|F|=\left|\frac{G m^{\prime}}{d^{2}{ }_{m 1-m 2}}\right|=\left|\frac{G m^{\prime}}{r^{2}+r^{\prime 2}-2 r r^{\prime} \cos (S)}\right|=\frac{G m^{\prime}}{r^{2}+r^{\prime 2}-2 r r^{\prime} \cos (S)}$

onde $\mathrm{d}_{\mathrm{m} 1-\mathrm{m} 2}$ é a distância entre a nave espacial e o corpo perturbador (calculado pela lei dos co-senos), $\mathrm{G}$ é a constante gravitacional, $\mathrm{S}$ é o ângulo entre a linha que liga o corpo e o centro de massa do corpo perturbado (a nave espacial) e a linha que liga o centro de massa do corpo e o corpo perturbador (terceiro corpo), $r$ é a distância a partir do satélite para o centro do sistema, e r' é a distância a partir do corpo perturbador até o centro do sistema. A última igualdade vem do fato de que a quantidade mostrada dentro do módulo é sempre positiva.

Desta forma, o integral da amplitude da força ao longo do tempo para um período do veículo espacial $\mathrm{T}$, que será chamado por PI (que significa "Perturbation Integral"), é dada por:

$$
P I=\int_{0}^{T} \frac{G m^{\prime}}{r^{2}+r^{\prime 2}-2 r r^{\prime} \cos (S)} d t
$$

que pode ser transformada em (Prado, 2013):
$P I=\frac{G m^{\prime}}{n} \int_{0}^{2 \pi} \frac{1}{r^{2}+r^{\prime 2}-2 r r^{\prime} \cos (S)}(1-e \cos (E)) d E$

Nessa forma, a PI pode ser avaliada por qualquer método numérico e ela mostra o nível de perturbação recebida pela nave espacial. Este critério tem algumas características que são interessantes:

1) É um critério dinâmico. Assim, o índice calculado depende da órbita específica da nave espacial e do modelo dinâmico adoptado;

2) Uma vez que as órbitas são keplerianas todo o tempo, é possível calcular este índice para cada perturbação individualmente. Desta forma, o efeito de cada força é avaliado quanto ao seu efeito integral para um período da órbita nominal pretendida para a nave espacial e é possível comparar esses números para decidir quais forças devem ser consideradas para o estudo do movimento da nave espacial, de acordo com a precisão requerida pelo estudo;

3) Para um dado par de órbitas (corpos perturbado e perturbador), este índice depende também da posição inicial dos corpos. Portanto, para ter uma visão completa, é interessante variar esta posição relativa. Isto pode ser feito através do estudo da evolução do índice em função do $\mathrm{M}_{0}^{\prime}$ em todo o intervalo de zero a $2 \pi$. No presente trabalho, conforme detalhado mais a frente, será utilizada a técnica de efetuar um processo de média para eliminar essa dependencia;

4) Este índice mede a quantidade de variação de velocidade trasmitida pela perturbação na nave espacial, que pode ser relacionada com o consumo de combustível necessário para manter a órbita kepleriana da nave espacial. Embora existam razões de engenharia a serem consideradas em manobras como essa (não idealidade de vários tipos de propulsão, estratégias de manobras que exploram a possibilidade de permitir desvios instantâneos na órbita nominal, etc), esse número identifica qual orbita é menos perturbada e então pode requerer menos consumo de combustível para as manobras. Logo é possível fazer um mapeamento que aponta as órbitas mais econômicas para serem utilizadas por uma nave espacial.

\section{Resultados}

A idéia é mostrar a evolução da PI ao longo do tempo das forças perturbadoras para uma nave espacial em torno do corpo principal do asteróide 2001SN263 perturbado pelos dois corpos menores, pelo Sol, pela Lua e pelos demais planetas do Sistema Solar. Para fazer este estudo, os dois corpos menores são assumidos em órbitas circulares ao redor do corpo maior, o Sol é assumido como estando em uma órbita elíptica em torno do centro do sistema de referencia (corpo maior), os planetas são assumidos em órbitas circulares em torno do Sol e a Lua, assumida estar em uma órbita circular um torno da Terra. Para o caso especial da Terra foi feita uma segunda simulação considerando sua órbita como elíptica em torno do Sol. Todo o movimento é assumido como ocorrendo dentro de um mesmo plano. Todos os dados físicos dos planetas utilizados 
estão mostrados na Tabela 1. Para a Lua foi utilizada uma distância média até a Terra de $384400 \mathrm{~km}$ e uma massa de $7,36 \times 10^{22} \mathrm{~kg}$.

Tabela 1: Massas e Distâncias Médias dos Planetas ao Sol

\begin{tabular}{|c|c|c|}
\hline Planeta & $\begin{array}{c}\text { Distância média ao } \\
\text { Sol }(\mathrm{km})\end{array}$ & Massa $(\mathrm{kg})$ \\
\hline Mercúrio & 57.910 .000 & $3,30200 \times 10^{23}$ \\
\hline Vênus & 108.200 .000 & $4,86900 \times 10^{24}$ \\
\hline Terra & 149.600 .000 & $5,9742 \times 10^{24}$ \\
\hline Marte & 227.940 .000 & $6,4191 \times 10^{23}$ \\
\hline Júpiter & 778.330 .000 & $1,8987 \times 10^{27}$ \\
\hline Saturno & 1.429 .400 .000 & $5,6851 \times 10^{26}$ \\
\hline Urano & 2.870 .990 .000 & $8,6849 \times 10^{25}$ \\
\hline Netuno & 4.504 .300 .000 & $1,0244 \times 10^{26}$ \\
\hline
\end{tabular}

Um ponto importante desta integral é que ela depende da configuração inicial, ou seja, da posição do corpo perturbador quando o movimento é iniciado. Para levar em conta este fato, em todas as simulações feitas no presente trabalho, o estudo dos efeitos das variações de cada elemento orbital é feita em função da anomalia da média inicial do corpo perturbador $\mathrm{M}_{0}^{\prime}$. Após isso é feita uma média ao longo de todos os possíveis valores dessa variável entre 0 e $2 \pi$, para que todas as situações sejam levadas em conta.

Deste modo, as Figuras 1 a 13 mostram o efeito da mudança de cada elemento orbital da nave espacial. É importante notar que, uma vez que esta integral é feita ao longo de um período de nave espacial, é necessário definir um valor de semi-eixo maior (assim, um período de revolução), para ser uma referência para os cálculos. Esta órbita é escolhida como sendo a órbita circular com semi-eixo maior de $10 \mathrm{~km}$, que fica entre os dois corpos menores, com um periodo de $254001 \mathrm{~s}$.

Os dados físicos e orbitais dos três componentes do sistema 2001SN263 são (Araújo et al., 2012):

Alpha (em torno do Sol): $\mathrm{a}=1,99 \mathrm{UA}, \mathrm{e}=0,48$, massa $=917,47 \times 10^{10} \mathrm{~kg}$;

Beta (em torno de Alpha): $\mathrm{a}=16,63 \mathrm{~km}$, inclinação $=0$, massa $=24,04 \times 10^{10} \mathrm{~kg}$;

Gama (em torno de Alpha): $\mathrm{a}=3.80 \mathrm{~km}$, inclinação de 14 graus, massa $=9,77 \times 10^{10} \mathrm{~kg}$.

A Figura 1 mostra a evolução da magnitude da força perturbadora devida ao corpo Beta como uma função da excentricidade da órbita da nave espacial. Os valores iniciais para os outros elementos orbitais são: $\mathrm{a}=10 \mathrm{~km}, \mathrm{i}=0, \omega=0, \Omega=0$ e a excentricidade assume os valores 0.0 e 0.65 . Após esse valor existem problemas de colisão que serão mais estudados no futuro, pois nessa região de excentricidades as órbitas se cruzam porque o apogeu da órbita do veículo espacial fica mais elevado que a órbita de Beta. Note um crescimento do valor de PI com a excentricidade. É possível explicar este resultado com base na geometria do sistema. Em uma órbita excêntrica, a nave espacial permanece mais tempo em maior altitude (assim, mais perto da órbita do corpo Beta) no apogeu da órbita e permanece menos tempo em uma altitude mais baixa (assim, longe da órbita do corpo Beta) no perigeu. Naturalmente, este efeito é aumentado quando a excentricidade cresce, e desaparece para uma órbita circular.

A Figura 2 mostra a evolução da magnitude da força perturbadora devido ao corpo Beta como uma função da inclinação da órbita da nave espacial. Os valores iniciais para os outros elementos orbitais são: $\mathrm{a}=10 \mathrm{~km}, \mathrm{e}=0, \omega=0, \Omega=0$. Nota-se que órbitas perpendiculares ao plano da órbita do corpo Beta são menos perturbadas, pois em média a nave espacial fica a uma distância menor do corpo pertuubador devido a terceira dimensão envolvida no problema.

No que diz respeito ao aumento do semi-eixo maior da órbita do veículo espacial, os resultados (Figura 3) mostram que o valor de PI aumenta com essa variável até o valor do semi-eixo do corpo Beta. Nesse ponto existe um pico e a partir daí passa a ocorrer um decrescimo até uma estabilização. Isto é esperado devido ao fato da perturbaçâo ser maior quando o corpo está mais próximo do corpo perturbador. Este resultado pode ser esperado, mas o cálculo deste integral quantifica os resultados.

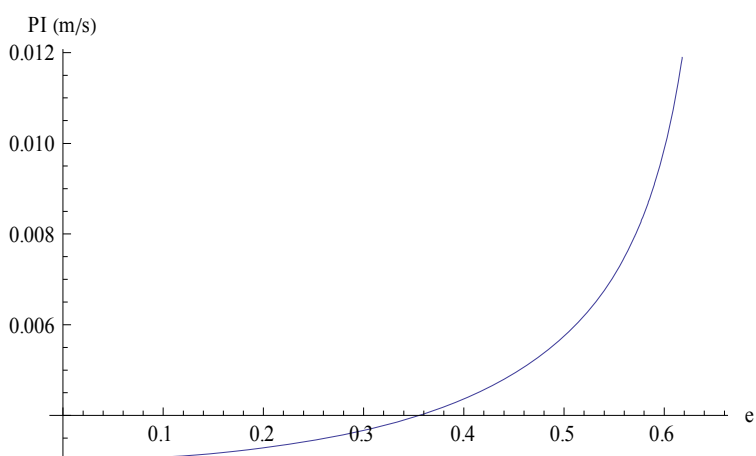

Fig. 1 - PI (m/s) como uma função da excentricidade da órbita do veículo espacial considerando apenas o corpo Beta como perturbador para uma órbita com semi-eixo maior de 10 km e inclinação zero.

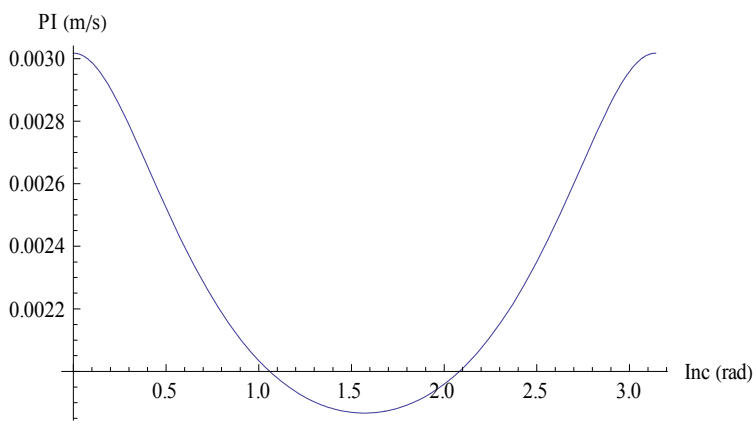

Fig. 2 - PI (m/s) como uma função da inclinação da órbita do veículo espacial considerando apenas o corpo Beta como perturbador para uma órbita circular com semi-eixo maior de $10 \mathrm{~km}$. 


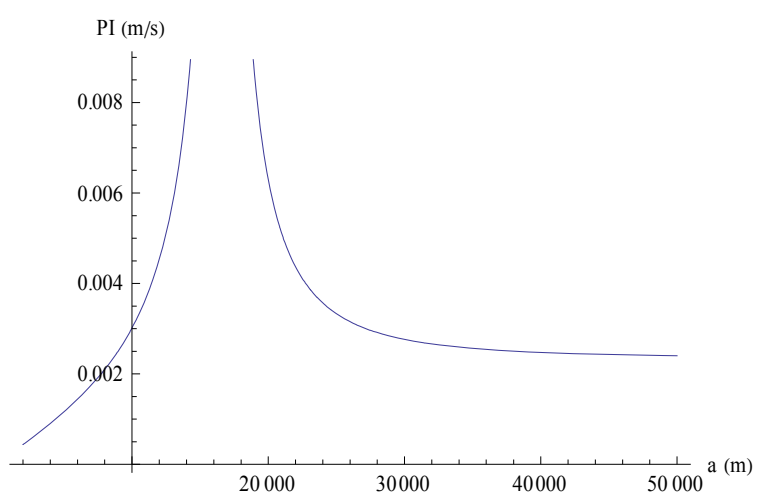

Fig. 3 - PI (m/s) como uma função do semi-eixo maior da órbita do veículo espacial considerando apenas o corpo Beta como perturbador para uma órbita circular com inclinação zero. Pico é em 1.4 $\mathrm{m} / \mathrm{s}$ e $\mathrm{a}=16630 \mathrm{~m}$

A figura 4 abaixo mostra o efeito da perturbação devida apenas ao Sol para uma órbita circular com semi-eixo maior de $10 \mathrm{~km}$ e inclinação zero. Note que o resultado tem a forma de uma senóide, indicando o fato da órbita do Sol ser elíptica e a perturbação ser maior quando o Sol está no perigeu do que quando está no apogeu. A diferença entre esses extremos é relativamente grande, da ordem de um fator cinco. Nota-se que a influência do Sol é de, no máximo, 2,5 x $10^{-5}$, e valor médio próximo de $1 \times 10^{-5}$, o que é cerca de 250 vezes menor que a influência do corpo Beta. Esse fato é devido as pequenas distâncias envolvidas no sistema triplo, fazendo com que o efeito diferencial do Sol no asteróide e no veículo espacial seja muito pequeno.

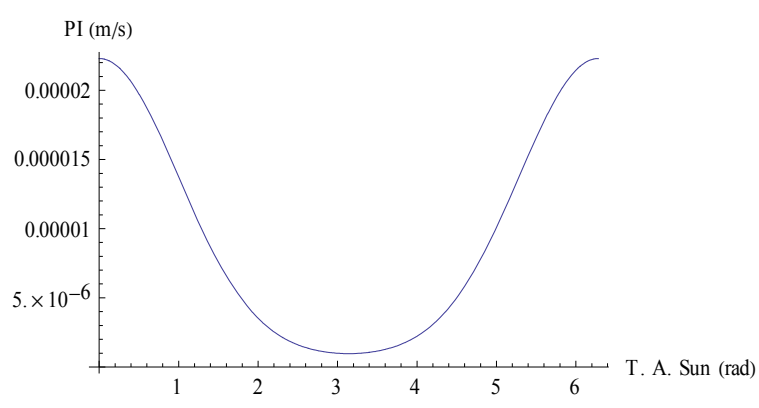

Fig. 4 - PI (m/s) como uma função da anomalia verdadeira do Sol considerando apenas o Sol como perturbador para uma órbita circular com semi-eixo maior de $10 \mathrm{~km}$ e inclinação zero.

As figuras 5 a 7 mostram os resultados equivalentes quando se considera apenas o corpo Gama como perturbador das órbitas. Os resultados são similares, pelas mesmas razões físicas já apontadas para o caso do corpo Beta, logo as explicações são omitidas aqui. Nota-se como fato novo que a ordem de grandeza do valor médio da perturbação é da ordem de seis vezes maior que o efeito de Beta, para órbitas com semieixo maior da ordem de $10 \mathrm{~km}$, e que chega a cerca de 10 vezes na região estabilizada (acima de $40 \mathrm{~km}$ ). A razão desse fato é a pequena distância do corpo
Alpha até o Gama. Apesar de ter menor massa que o corpo Beta, o corpo Gama altera a órbita do corpo Alpha de forma significativa e isso faz com que a órbita do veículo espacial seja alterada. Em outras palavras, o termo indireto de Gama é forte o bastante para perturbar uma órbita mais do que o corpo Beta, de maior massa.

Nota-se também na Fig. 5 um pico para e $=0.62$. Isso ocorre porque o perigeu da órbita padrão de $\mathrm{a}=$ $10 \mathrm{~km}$ tem perigeu coincidente com a órbita de Gama e isso gera uma grande aproximação entre os corpos com esse valor de excentricidade. Após esse valor ainda existem cruzamentos entre as órbitas, mas eles são cada vez mais rápidos e contribuem menos para a integral do que a situação onde o apogeu coincide com a órbita de Gama, pois a passagem pelo apogeu é mais lenta, pela Lei de Kepler. Na Fig. 6 nota-se um desvio no valor de máximo da função PI, devido a inclinação na órbita de Gama. O valor máximo é sempre para uma órbita coplanar com o perturbador. Na Fig. 7 nota-se o pico em a $=3800 \mathrm{~m}$, que corresponde ao raio da órbita de Gama.

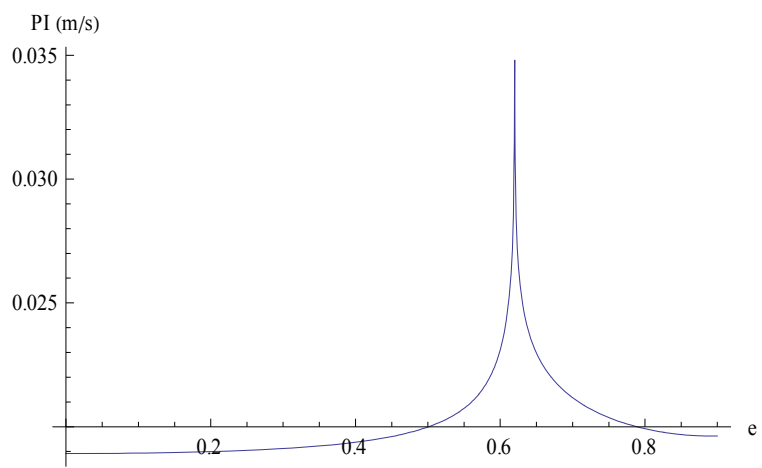

Fig. 5 - PI (m/s) como uma função da excentricidade da órbita do veículo espacial considerando apenas o corpo Gama como perturbador para uma órbita com semi-eixo maior de $10 \mathrm{~km}$ e inclinação zero.

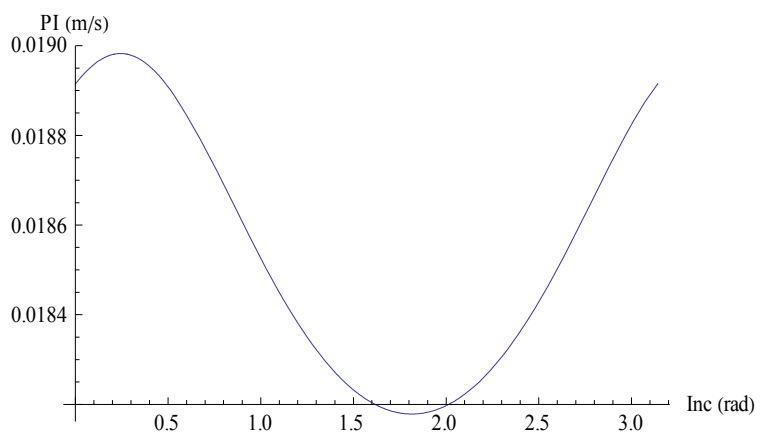

Fig. 6 - PI (m/s) como uma função da inclinação da órbita do veículo espacial considerando apenas o corpo Gama como perturbador para uma órbita circular com semi-eixo maior de $10 \mathrm{~km}$.

As figuras 8 a 10 mostram os resultados equivalentes quando se consideram os corpos Beta e Gama como perturbadores das órbitas. Os resultados são similares, pelas mesmas razões físicas já apontadas. Nota-se como fato novo que a ordem de grandeza do 
valor médio da perturbação é apenas levemente superior a valor obtido apenas com o corpo Gama, quando consideradas órbitas com semi-eixo maior de 10 $\mathrm{km}$. No caso do efeito do semi-eixo maior nota-se a presença de dois picos nos valores de PI, devido as proximidades dos dois corpos perturbadores.

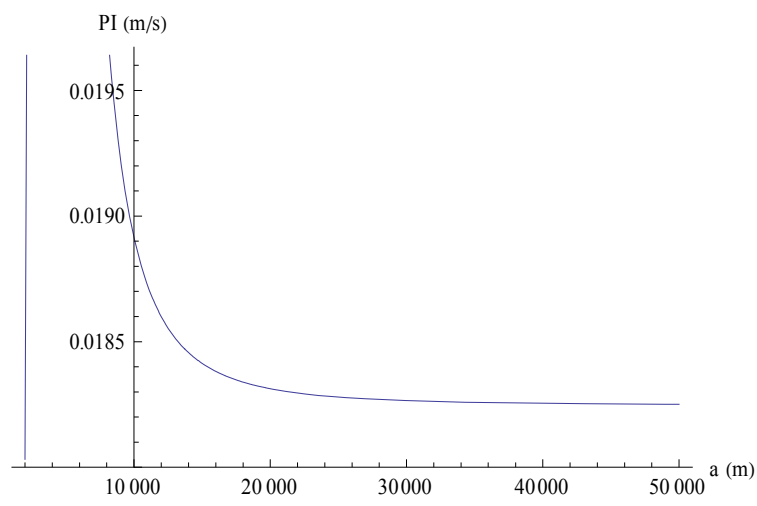

Fig. 7 - PI (m/s) como uma função do semi-eixo maior da órbita do veículo espacial considerando apenas o corpo Gama como perturbador para uma órbita com inclinação zero. Pico é em PI $=0.17 \mathrm{~m} / \mathrm{s}$ e $\mathrm{a}=3800 \mathrm{~m}$.

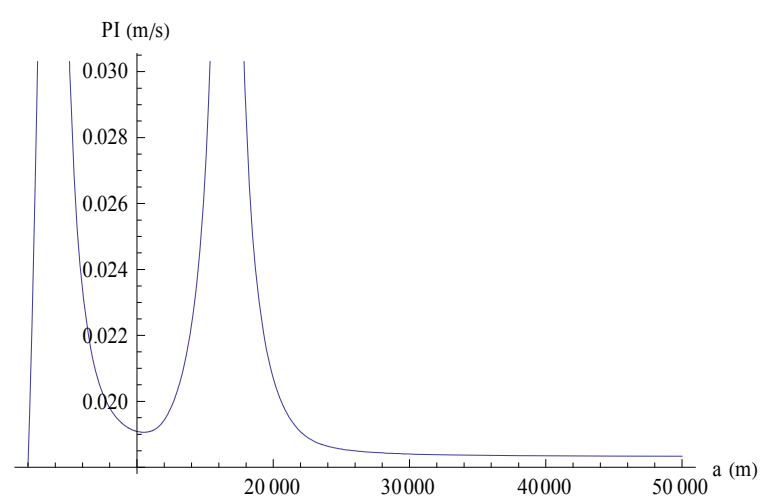

Fig. 8 - PI (m/s) como uma função do semi-eixo maior da órbita do veículo espacial considerando os corpos Beta e Gama como perturbadores para uma órbita circular com inclinação zero. Picos são em 0.2 $\mathrm{m} / \mathrm{s}$ a esquerda e $1.2 \mathrm{~m} / \mathrm{s}$ a direita.

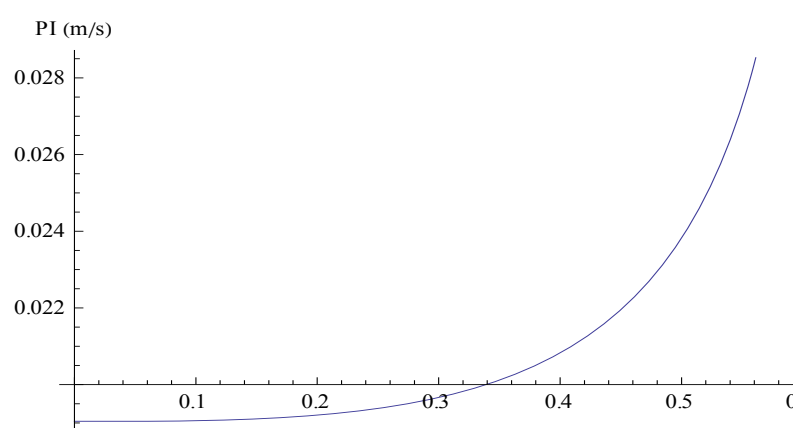

Fig. 9 - PI (m/s) como uma função da excentricidade da órbita do veículo espacial considerando os corpos Beta e Gama como perturbadores para uma órbita com semi-eixo maior de $10 \mathrm{~km}$ e inclinação zero.

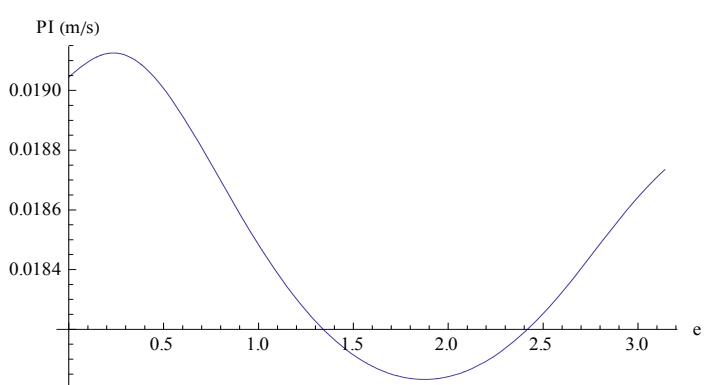

Fig. 10 - PI (m/s) como uma função da inclinação da órbita do veículo espacial considerando os corpos Beta e Gama como perturbadores para uma órbita circular com inclinação zero.

A seguir estuda-se o efeito das perturbações causadas pelos planetas do Sistema Solar. Como trata-se de uma estimativa comparativa dos efeitos perturbadores, é assumido que os planetas sigam órbitas circulares em torno do Sol com as distâncias médias dadas pela Tabela 1. Os valores utilizados para as massas dos respectivos planetas também estão mostrados na mesma Tabela. Foi calculado o fator PI como uma função das anomalias verdadeiras do Sol (T. A. Sun) e do planeta (T. A. Earth, no caso mostrado na Fig. 11, onde as perturbações do planeta Terra são consideradas). Nota-se um pico próximo da região onde a anomalia verdadeira do Sol é perto de zero e a da Terra perto de $\pi$, que equivale à situação aonde a Terra esta mais próxima do asteroide. Uma simulação considerando a órbita da Terra com semieixo maior de $149598261 \mathrm{~km}$ e excentricidade de 0.0106 foi feita. Os resultados mostraram um aumento significativo da perturbação, com um valor de pico em $10^{-5}$ e um valor médio de $5.55 \times 10^{-9}$.

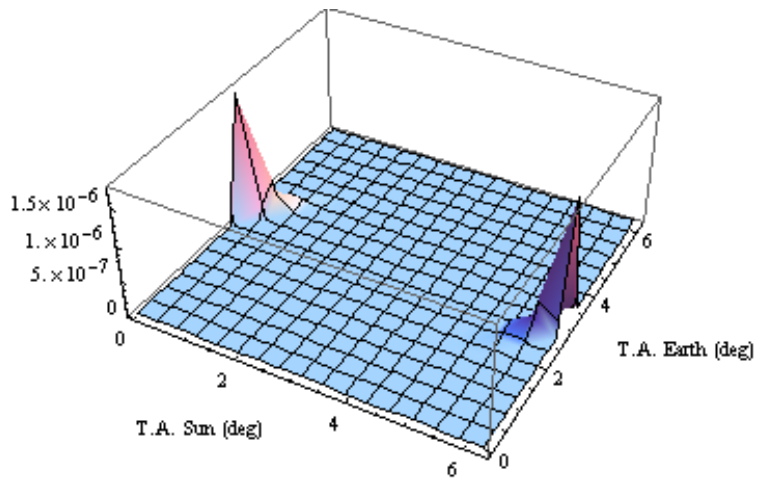

Fig. 11 - PI (m/s) como uma função das anomalias verdadeiras do Sol e da Terra, considerando a apenas a perturbação da Terra em órbita circular, para uma órbita circular com semi-eixo maior de $10 \mathrm{~km}$ e inclinação zero.

A Fig. 12 mostra o caso aonde a perturbação é devida ao planeta Marte. Note a existência de dois picos, que correspondem aos dois pontos aonde as órbitas de Marte e do asteroide se cruzam, logo a distância entre eles se reduz bastante. Note pela Ta- 
bela 2 que Marte apresenta um valor médio de perturbação muito superior ao dos demais planetas, devido a grande magnitude da perturbação nos instantes de cruzamento entre as órbitas.

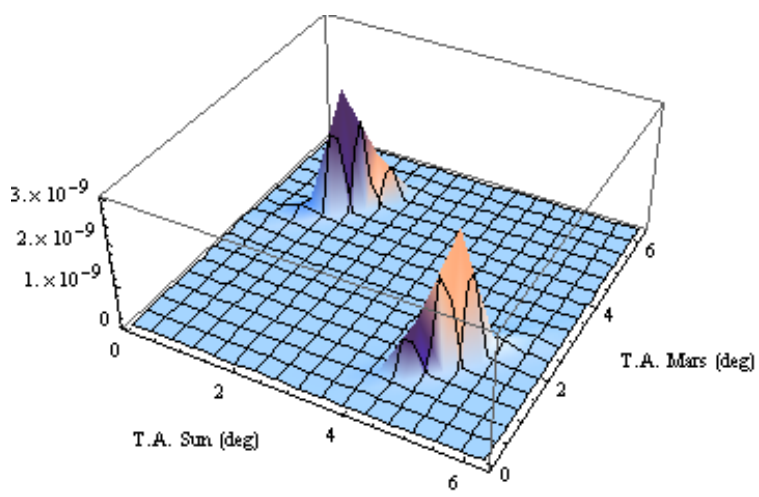

Fig. 12 - PI (m/s) como uma função das anomalias verdadeiras do Sol e de Marte, considerando a apenas a perturbação de Marte, para uma órbita circular com

semi-eixo maior de $10 \mathrm{~km}$ e inclinação zero.

Após esse estudo foi realizada uma média dupla para eliminar as dependências de PI em relação as anomalias verdadeiras do Sol e do planeta considerado. Com isso obteve-se um valor médio em relação as posições relativas dos dois corpos para cada planeta. Os resultados estão mostrados na Fig. 12, que mostra o valor de pico da perturbação e o respectivo valor médio. Note que Marte é o planeta que mais perturba as órbitas, em termos de valor médio, devido ao fato das órbitas se cruzarem e isso gerar uma contribuição grande nesses instantes para a perturbação total.

Em seguida foi estudada a perturbação da Lua, assumida como em órbita circular em torno da Terra. A Fig. 13 mostra o resultado obtido, como função das anomalias verdadeiras da Terra e da Lua. O Sol foi assumido como estando no ponto mais próximo do asteroide (perihelio da órbita do asteróide), para maximizar os efeitos.

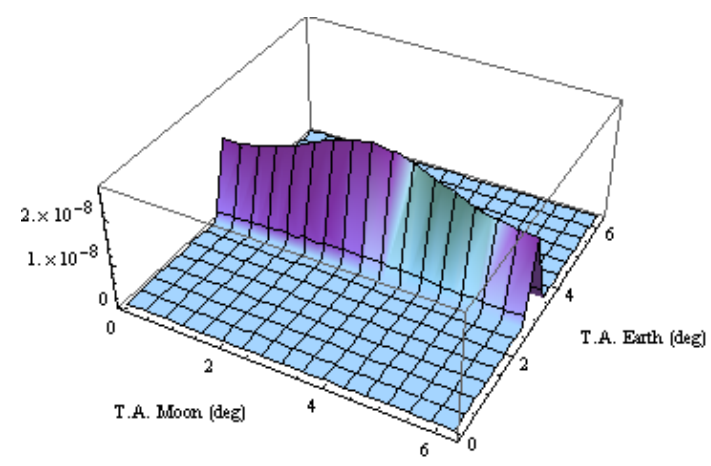

Fig. 13 - PI (m/s) como uma função das anomalias verdadeiras da Lua e da Terra, considerando a apenas a perturbação da Lua, para uma órbita circular com semi-eixo maior de 10 km e inclinação zero.
Tabela 2: Perturbações Devidas aos Planetas

\begin{tabular}{|l|l|l|}
\hline \multicolumn{1}{|c|}{ Planeta } & \multicolumn{1}{c|}{ Pico } & \multicolumn{1}{c|}{ Valor Médio } \\
\hline Mercurio & $1.5 \times 10^{-11}$ & $1.99 \times 10^{-12}$ \\
\hline Venus & $2.0 \times 10^{-9}$ & $6.96 \times 10^{-11}$ \\
\hline Terra & $1.5 \times 10^{-6}$ & $2.13 \times 10^{-9}$ \\
\hline Lua & $2.0 \times 10^{-8}$ & $2.63 \times 10^{-11}(4$ integrais $)$ \\
\hline Marte & $3.0 \times 10^{-9}$ & $2.91 \times 10^{-5}$ \\
\hline Jupiter & $2.0 \times 10^{-9}$ & $2.38 \times 10^{-10}$ \\
\hline Saturno & $2.0 \times 10^{-11}$ & $8.86 \times 10^{-12}$ \\
\hline Urano & $2.5 \times 10^{-13}$ & $1.56 \times 10^{-13}$ \\
\hline Netuno & $6.0 \times 10^{-14}$ & $4.70 \times 10^{-14}$ \\
\hline
\end{tabular}

\section{Conclusões}

Este trabalho utilizou um novo conceito para mapear órbitas levando em consideração os efeitos das perturbações sofridas por um veículo espacial em órbita do corpo principal do asteróide 2001SN263. Esse conceito avalia o efeito das perturbações através do calculo da integral dos efeitos perturbativos ao longo do tempo, como forma de não ficar restrito a posoções específicas das órbitas.

Essa idéia é então aplicada à perturbação de um terceiro corpo incluído na dinâmica e os resultados numéricos são avaliados para o Sol, os corpos Beta e Gama, a Lua e todos os planetas do Sistema Solar como corpos perturbadores.

Detectou-se que o corpo Gama é o perturbador principal, seguido por Beta, devido ao termo indireto da função peturbadora ser grande pela proximidade entre Alpha e Gama. O Sol tem uma pequena contribuição, assim como os demais planetas do Sistema Solar e a Lua. Marte possui uma componente maior, em termos de valor médio, devido ao fato de sua órbita cruzar com a órbita do asteroide. A Terra em órbita elíptica vem logo depois.

Os efeitos dos elementos keplerianos da órbita do veículo espacial são mostrados em detalhes. É visível que as órbitas circulares são menos perturbadas, que as órbitas inclinadas tem valores mínimos e que o semi-eixo maior tem perturbações mais fortes quando perto dos principais corpos perturbadores.

\section{Agradecimentos}

Agradecemos ao CNPQ, FAPESP e CAPES pelo apoio nesta pesquisa.

\section{Referências Bibliográficas}

Prado, Antonio F. Bertachini A. . Searching for Orbits with Minimum Fuel Consumption for Station-Keeping Maneuvers: An Application to Lunisolar Perturbations. Mathematical Problems in Engineering (Print), v. 2013, p. 1-11, 2013.

DOI: $10.1155 / 2013 / 854317$

Araujo, R. A. N.; WINTER, O. C. ; Prado, A.F.B.A. ; Sukhanov, A. . Stability regions around the components of the triple system 2001SN263. Monthly Notices of the Royal Astronomical So

Sukhanov, A.; Velho, H. F. C.; Macau, E.; Winter, O. The Aster Project: Flight to a Near-Earth Asteroid 443-450, 2010. 